\title{
Numerical Investigation of Penetration Characteristics of Preformed Spherical Fragments at Hyper Velocity
}

\section{DOI : 10.36909/jer.ICCEMME.15597}

\author{
Pradeep Mulabagal*, Adepu Kumaraswamy*, Ambuj Saxena** \\ *Department of Mechanical Engineering, Defence Institute of Advanced Technology, Pune, \\ 411025, India. \\ **Department of Mechanical Engineering, G. L. Bajaj Institute of Technology and \\ Management, Greater Noida, 201306, India. \\ *Corresponding Author: adepu_kswamy@yahoo.com
}

\begin{abstract}
Numerical investigation of penetration characteristics of $6 \mathrm{~mm} \mathrm{SS304} \mathrm{preformed} \mathrm{spherical}$ fragments released from a Fragment Generator Warhead (FGW) impacting on Steel 1006 target plate of $1 \mathrm{~mm}, 3 \mathrm{~mm}$ and $6 \mathrm{~mm}$ thick in velocity range $1000 \mathrm{~m} / \mathrm{s}$ to $5000 \mathrm{~m} / \mathrm{s}$ and impact angle between $0^{\circ}$ and $75^{\circ}$, has been carried out using the explicit code LS-Dyna which is predominantly used for solving impact problems. The simulation model employs a strain rate dependent plasticity model viz. Johnson-Cook model supplemented by Gruneisen Equation of State (EoS), to capture the large strain encountered in target plate due to impact of a spherical fragment at high velocities. The simulation model results are presented in terms of crater diameter on the target plate normalised over original fragment diameter. Empirical equations are available in literature to estimate the normalised crater diameter under the same impact conditions employed in simulation models. The simulation model results have been validated with experimental data available in literature and also found to be in good agreement with the results obtained from empirical equations. The effectiveness of the erosion contact algorithm over Smoothed Particle Hydrodynamics (SPH) method in LS-Dyna to reasonably predict the behaviour of the target material at high velocities of impact is demonstrated in the current study.
\end{abstract}


Keywords: LS-Dyna; impact; erosion contact; normalised crater diameter; hyper velocities; empirical equation; Fragment Generator Warhead; SPH.

\section{INTRODUCTION}

The terminal ballistics is an area of great interest for research in design of structures for fortification, especially for military defence. Projectile velocity is a fundamental quantity in terminal ballistics. Even though various other parameters affect the target response, the projectile velocity is a predominant parameter that overrides most other considerations. Broad classification of the projectile velocity regimes (Backman et al., 1978) is listed in Table 1.

Table 1 Impact velocity regimes

\begin{tabular}{|l|c|l|}
\hline \multicolumn{2}{|c|}{ Velocity } & \multicolumn{2}{c|}{ Examples } \\
\hline \multicolumn{1}{|c|}{ Regime } & Range (m/s) & \multicolumn{1}{|c}{} \\
\hline Ordnance & $500-1300$ & $\begin{array}{l}\text { Military projectiles like bullets, missiles, fragments of } \\
\text { explosives. }\end{array}$ \\
\hline $\begin{array}{l}\text { Ultra- } \\
\text { ordnance }\end{array}$ & $1300-3000$ & Warhead fragments, rocket busted penetrators. \\
\hline Hypervelocity & $>3000$ & All kinds of space vessels exposed to meteoroid impact. \\
\hline
\end{tabular}

Fragment Generator Warheads (FGW) are predominantly used in surface to air type missile systems to destroy distant targets. The FGW carry preformed fragments of various shapes viz. spherical, conical, cubical, blunt etc. These preformed fragments are propelled by a missile system which detonates at close proximity of a target, so that the fragments impact on the target surface at a very high velocity and cause maximum damage. Experimental study on FGW with spherical and cubical fragments impacting at ultra-ordnance velocity range is available in literature (Dhote et al., 2014 \& Dhote et al., 2015). This paper deals with the numerical study of impact dynamics of the spherical fragments in the velocity range from ordnance to hypervelocity. High projectile velocity impact problems are associated with high strain rate, large deformation, erosion and fragmentation. Numerical methods and corresponding computing techniques can predict such complex material deformation behaviour.

LS-Dyna is an explicit code predominantly used in the design industry to predict high strain rate dependent non-linear behaviour of materials by applying various simulation 
approaches. A meshless Lagrangian numerical method, Smooth Particle Hydrodynamics (SPH), is widely used in multiple explicit codes to resolve impact problems associated with large geometric distortions. However, SPH method consumes large computation time and requires a high-end computer hardware configuration. In the current study, numerical analysis has been carried out using an erosion contact algorithm in LS-Dyna, which consumes less computation time and comparatively requires a low-end hardware configuration.

In this paper, numerical investigation of penetration characteristics of $6 \mathrm{~mm} \mathrm{SS304}$ preformed spherical fragments released from a FGW upon impacting a Steel 1006 target plate of 1,3 and $6 \mathrm{~mm}$ thick at velocity ranging from $1000 \mathrm{~m} / \mathrm{s}$ to $5000 \mathrm{~m} / \mathrm{s}$ (in steps of $500 \mathrm{~m} / \mathrm{s}$ ) and impact angle between $0^{\circ}$ to $75^{\circ}$ (in steps of $15^{\circ}$ ) from the axis, normal to the plate surface, has been carried out using erosion contact algorithm in LS-Dyna. Johnson-Cook (J-C) constitutive material model (Jhonson et al., 1983) is widely used in explicit codes to simulate the high strain rate deformation behaviour of materials. Also, Equation of State (EOS) relates the hydrostatic pressure, local density and local specific energy in material to describe its hydrodynamic response under shock loading and also to supplement the constitutive material model. In this study, J-C model is supplemented with Gruneisen EOS in the simulation models. The simulation model results are presented in terms of crater diameter formed on the target plate due to impact, normalised over original fragment diameter. Also, empirical equations are available in literature to estimate the crater diameter on the target plate for normal and oblique impact of the spherical fragments up to hyper velocities of impact (Hosseini et al., 2006 \& Hill, 2004). A comparative study of the crater diameter measured from simulation models and empirical models have also been carried out in the current study.

\section{FINITE ELEMENT MODELING}

A simulation model is developed in LS-Dyna R7.1.1 software with SS304 spherical fragment of 6mm diameter and Steel 1006 target plate with $60 \mathrm{~mm}$ diameter, as shown in Figure 1. The 
spherical fragment and target plate are discretised with 8-noded hexahedral elements. Mesh convergence of target plate has been carriedout to optimise the element size and CPU run time.
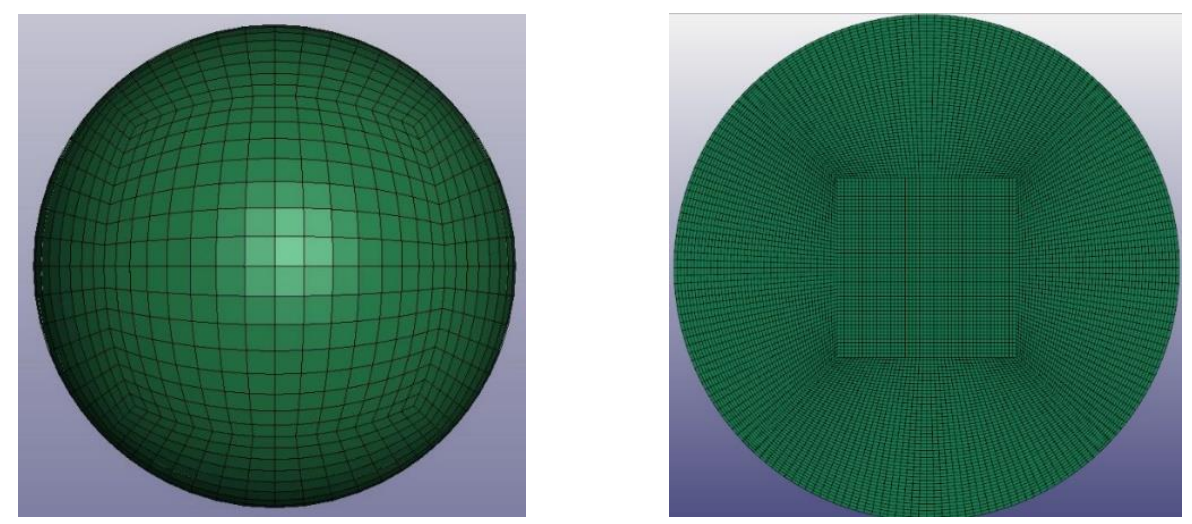

Figure 1 Spherical Fragment (6mm diameter) \& Plate (60 mm diameter) in LS Dyna Model

The LS Dyna simulation model consists 28672 elements of the spherical fragment and $61500 / 184500 / 369000$ elements of the target plate of $1 / 3 / 6 \mathrm{~mm}$ thickness. In order to ensure the numerical accuracy, the target plate is meshed with a fine mesh near the impact region and coarse mesh away from the contact region. The translational nodal degrees of freedom along the boundary of the target plate are constrained to prevent any translational motion. A Lagrangian processor, is computationally fast and gives good definition of material interfaces, in which the numerical grid distorts with the material. However, by using an erosion contact algorithm, the Lagrangian processors attain an enhanced ability to simulate large deformation events. The erosion algorithm works by removing Lagrangian zones, which have reached a user-specific strain, typically of the order of $100-150 \%$.

LS-Dyna recommends use of eroding contact types whenever solid elements involved in the contact definition are subjected to erosion (element deletion) due to material failure criteria. So CONTACT_ERODING_NODE_TO_SURFACE algorithm has been considered in the current study. LS-Dyna also has a large variety of material models. The material model with keyword MAT_JOHNSON_COOK and damage equations supplemented by EOS_GRUNEISEN equation of state is used to describe the material behaviour of both spherical fragment and target plate. The material properties of SS304 fragment and Steel 1006 target plate 
used in J-C model and Gruneisen EOS are listed in Table 2 (Dhote et al., 2017) and Table 3

(Gintalas et al., 2014).

Table 2 Target plate and fragment material parameters for J-C Model \& Gruneisen EOS

\begin{tabular}{|l|c|c|c|}
\hline \multirow{2}{*}{ Property } & \multirow{2}{*}{ Unit } & \multicolumn{2}{c|}{ Material } \\
\cline { 3 - 4 } & & SS304 & Steel 1006 \\
\hline Density & $k g / m$ & 7896 & 7896 \\
\hline Poisson's ratio & - & 0.3 & 0.3 \\
\hline Gruneisen coefficient $(\gamma)$ & - & 1.93 & 2.17 \\
\hline Hugoniot sound speed $(C)$ & $m / s$ & 4570 & 4569 \\
\hline Hugoniot constant $\left(S_{1}\right)$ & - & 1.49 & 1.49 \\
\hline Young modulus & $G P a$ & 210 & 210 \\
\hline Shear modulus & $G P a$ & 77 & 81.8 \\
\hline Yield stress $(A)$ & $M P a$ & 310 & 350 \\
\hline Hardening constant $(B)$ & $M P a$ & 1000 & 275 \\
\hline Hardening constant $(n)$ & - & 0.65 & 0.36 \\
\hline Strain rate constant $(c)$ & - & 0.07 & 0.022 \\
\hline Thermal softening exponent $(m)$ & - & 1 & 1 \\
\hline Melting temperature & $K$ & 1673 & 1673 \\
\hline Room temperature & $K$ & 300 & 300 \\
\hline Sound speed & $m / s$ & 5406 & 5406 \\
\hline
\end{tabular}

Table 3 Johnson-Cook Damage Model Parameters

\begin{tabular}{|c|c|c|}
\hline Parameter & Fragment & Plate \\
\hline$D_{1}$ & 0.05 & -0.8 \\
\hline$D_{2}$ & 3.44 & 2.1 \\
\hline$D_{3}$ & -2.12 & 0.5 \\
\hline$D_{4}$ & 0.002 & 0.0002 \\
\hline$D_{5}$ & 0.61 & 0.61 \\
\hline
\end{tabular}

Table 4 Simulation results Vs Experimental results

\begin{tabular}{|c|c|c|}
\hline \multirow{2}{*}{$\begin{array}{c}\text { Impact Velocity/ } \\
\text { Obliquity Angle }\end{array}$} & \multicolumn{2}{|c|}{ Crater Diameter (mm) } \\
\cline { 2 - 3 } $2000 \mathrm{~m} / \mathrm{s} / 0^{\circ}$ & Experimental & Simulation \\
\hline $2300 \mathrm{~m} / \mathrm{s} / 65^{\circ}$ & $\begin{array}{c}\text { Minor } \varphi: 8.8 \\
\text { Major } \varphi: 17.9\end{array}$ & $\begin{array}{l}\text { Minor } \varphi: 9.56 \\
\text { Major } \varphi: 18.63\end{array}$ \\
\hline
\end{tabular}



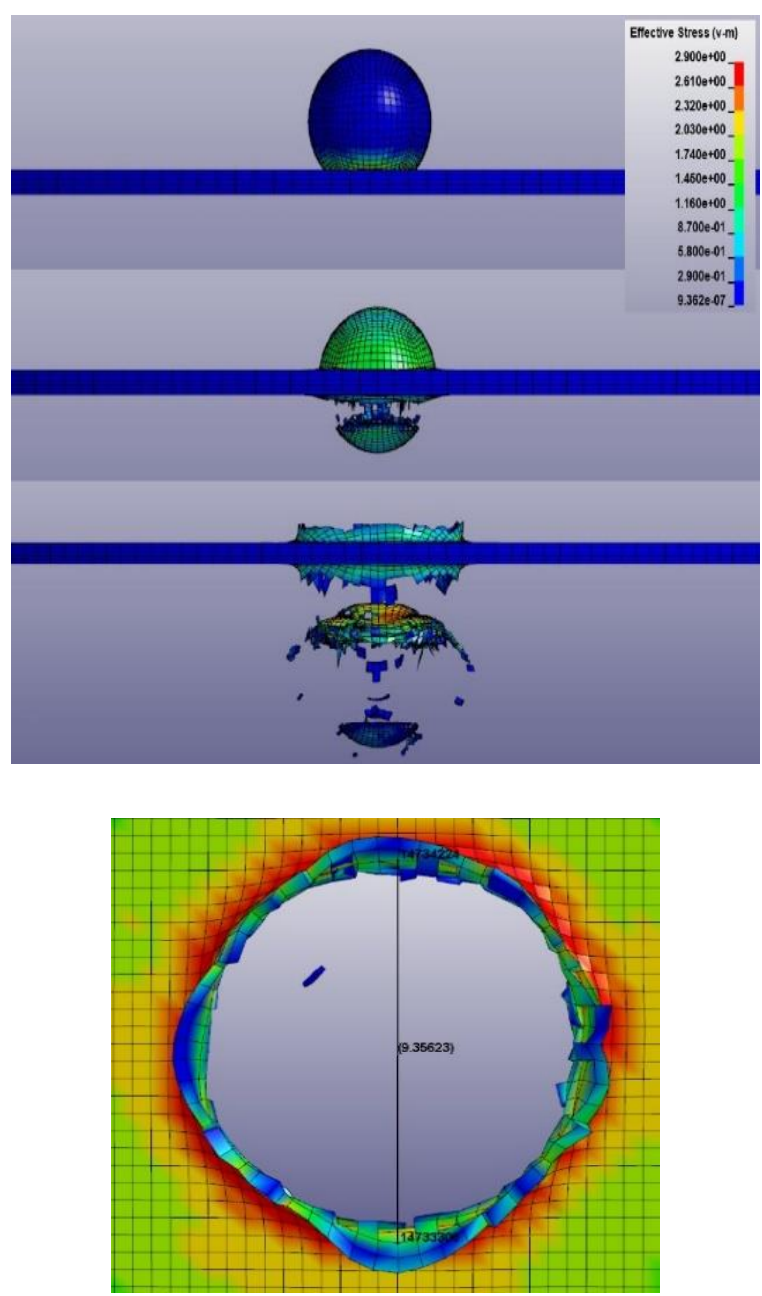

(a) $2000 \mathrm{~m} / \mathrm{s} / 0^{\circ}$ (Normal impact)
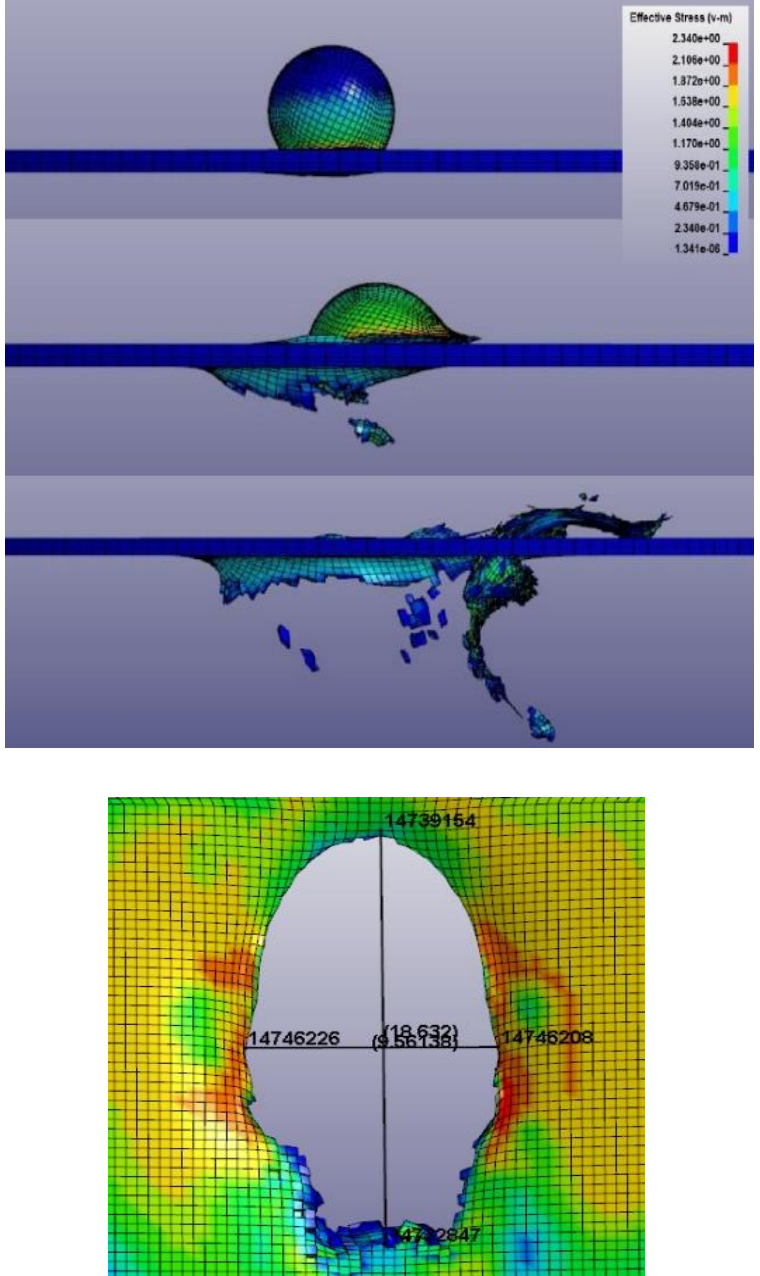

(b) $2300 \mathrm{~m} / \mathrm{s} / 65^{\circ}$ (Oblique impact)

Figure 2 Crater hole shapes obtained from simulation models

The simulation model results obtained in terms of crater diameter have been validated with experimental results in literature (Dhote et al., 2017) for a $6 \mathrm{~mm}$ diameter spherical fragment and $1 \mathrm{~mm}$ thick target plate under two impact conditions as tabulated in Table 4. A deviation of $2 \%$ to $9 \%$ in simulation results is observed from the experimental results. In case of normal impact, as shown in Figure 2(a), the perforation is circular, whereas, in case of an oblique impact the perforation has minor axis perpendicular to the plane of obliquity and major axis along the plane. The hole shapes in Figure 2(b) depict the oblique impact conditions, where the projectile enters from the top of the picture. The lethal fragment debris available on top is less due to sweeping action in oblique impact, accumulating more fragments at the bottom, causing a wider hole. It is evident from Table 4 and Figure 2 that the simulation results are relatively close to the 
experimental data (Dhote et al., 2017), which validates the correctness of the LS Dyna simulation model code used in the current study. The validated simulation model code is extrapolated to different thicknesses of the target plate for analysing the material deformation behaviour in the range of impact velocity and angle.

\section{SIMULATION MODEL RESULTS}

LS Dyna simulation models for a total of 189 cases are computed. The simulation models for 6 $\mathrm{mm}$ diameter spherical fragment impacting on $1 \mathrm{~mm} / 3 \mathrm{~mm} / 6 \mathrm{~mm}$ thick target plate at impact velocities from $1000-5000 \mathrm{~m} / \mathrm{s}$ and oblique impact angles from $0^{\circ}-75^{\circ}$ are computed.

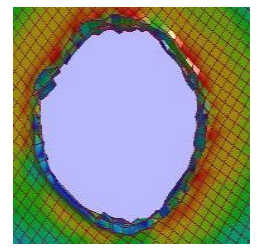

(a) $0^{\circ}$

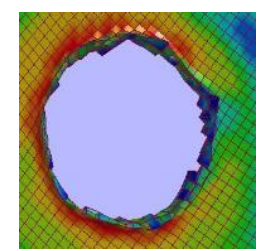

(b) $15^{\circ}$

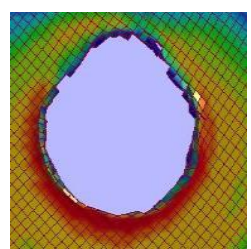

(c) $30^{\circ}$

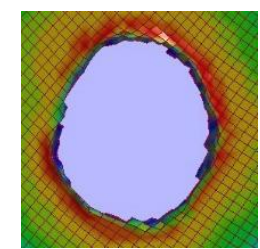

(d) $35^{\circ}$

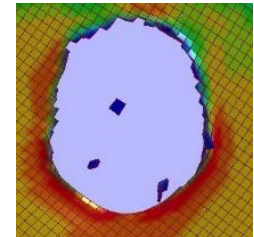

(e) $45^{\circ}$

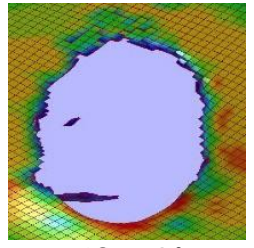

(f) $60^{\circ}$

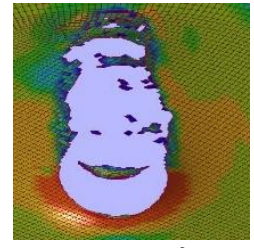

(g) $75^{\circ}$

Figure 3 Crater shapes on $1 \mathrm{~mm}$ plate at impact velocity $2000 \mathrm{~m} / \mathrm{s}$ and impact angle $0^{\circ}-75^{\circ}$

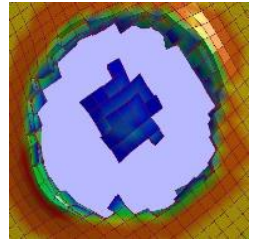

(a) $0^{\circ}$

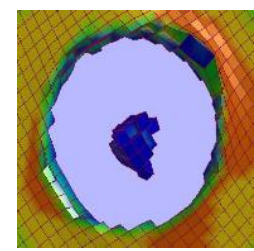

(b) $15^{\circ}$

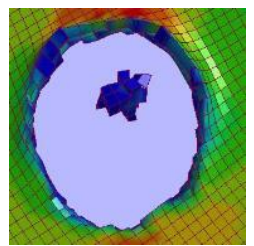

(c) $30^{\circ}$

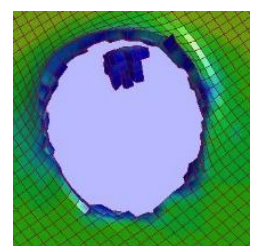

(d) $35^{\circ}$

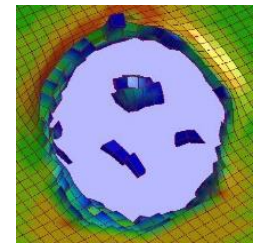

(e) $45^{\circ}$

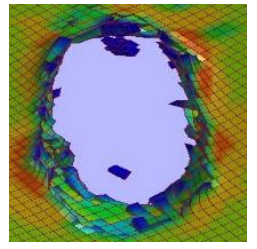

(f) $60^{\circ}$

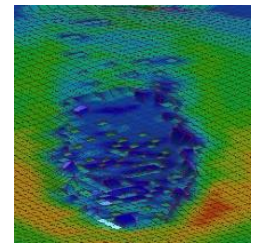

(g) $75^{\circ}$

Figure 4 Crater shapes on $3 \mathrm{~mm}$ plate at impact velocity $2000 \mathrm{~m} / \mathrm{s}$ and impact angle $0^{\circ}-75^{\circ}$

The crater shapes obtained on a $1 \mathrm{~mm}$ target plate at $2000 \mathrm{~m} / \mathrm{s}$ impact velocity and impact angles from $0^{\circ}-75^{\circ}$ are shown in Figure 3. The crater shape changed from circular to elliptical 
with the increase in impact angle. Similarly, the crater shapes obtained on a $3 \mathrm{~mm}$ target plate at $2000 \mathrm{~m} / \mathrm{s}$ impact velocity and impact angles from $0^{\circ}-75^{\circ}$ are shown in Figure 4 . It is observed from Figure 4 that the crater hole is circular for impact angles from $0^{\circ}-45^{\circ}$ and elliptical for $60^{\circ}$ impact angle. However, at impact angle $75^{\circ}$, the plate is eroded without perforation due to ricochet of the fragment. The crater shapes obtained on a $6 \mathrm{~mm}$ target plate at $2000 \mathrm{~m} / \mathrm{s} \mathrm{impact}$ velocity and impact angles from $0^{\circ}-75^{\circ}$ are shown in Figure 5. It is observed from Figure 5 that when the plate thickness and fragment diameter are same, there is only erosion without any penetration beyond $45^{\circ}$. The extent of erosion increased with an increase in impact velocity. The amount of fragment mass required to perforate the plate thickness is not sufficient in this case.

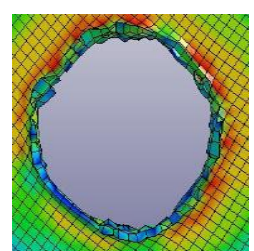

(a) $0^{\circ}$

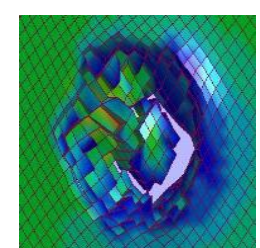

(b) $15^{\circ}$

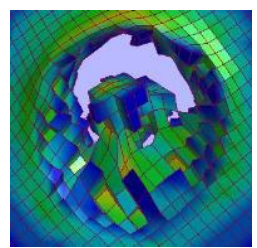

(c) $30^{\circ}$

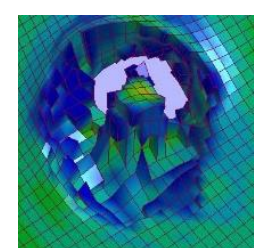

(d) $35^{\circ}$

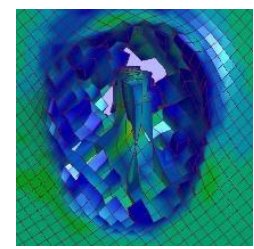

(e) $45^{\circ}$

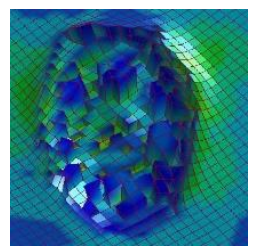

(f) $60^{\circ}$

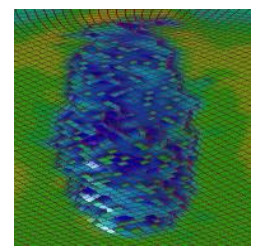

(g) $75^{\circ}$

Figure 5 Crater shapes on $6 \mathrm{~mm}$ plate at impact velocity $2000 \mathrm{~m} / \mathrm{s}$ and impact angle $0^{\circ}-75^{\circ}$

\section{EMPIRICAL RESULTS}

A generalised form of non-dimensional empirical formulae to calculate the ratio of crater hole diameter to the fragment diameter is given by Equation 1 (Hosseini et al., 2006 \& Hill, 2004). This equation relates the diameter ratio of crater hole in the plate to the projectile $\left(D_{h} / D_{p}\right)$ with velocity ratio $\left(V / c_{p}\right)$, density ratio $\left(\rho_{p} / \rho_{t}\right)$, target plate thickness to projectile diameter $\left(T_{t} / D_{p}\right)$ and function of impact obliquity. Three equations are derived from Equation 1 for the cases of normal and oblique angles of impact. For normal impact, crater hole ratio equation is given by Equation 2 and for oblique impact, since the shape of the crater is elliptical, the minor and major axis diameter of the crater hole is given by Equation 3 and Equation 4, respectively. The sound 
speed in the fragment and plate material is considered to be $6.02 \mathrm{~km} / \mathrm{s}$ (Dhote et al., 2017). The nomenclature of the parameters used in empirical formulae is given in Table 5.

$$
\begin{aligned}
& \frac{D_{h}}{D_{p}}=C_{1}\left(\frac{\rho_{p}}{\rho_{t}}\right)^{p 1}\left(\frac{V}{c_{t}}\right)^{p 2}\left(\frac{V}{c_{p}}\right)^{p 3}\left(\frac{T_{t}}{D_{p}}\right)^{p 4} f(\theta)+C_{2} \\
& \frac{D_{h}}{D_{p}}=C_{1}\left(\frac{V}{c_{t}}\right)^{p 1}\left(\frac{T_{t}}{D_{p}}\right)^{p 2} \\
& \frac{D_{h}^{\text {min }}}{D_{p}}=C_{1}\left(\frac{V}{c_{t}}\right)^{p 1}\left(\frac{T_{t}}{D_{p}}\right)^{p 3} \cos ^{p 3} \theta+C_{2} \\
& \frac{D_{h}^{\text {maj }}}{D_{p}}=C_{1}\left(\frac{V}{c_{t}}\right)^{p 1}\left(\frac{T_{t}}{D_{p}}\right)^{p 2} \mathrm{e}^{p 3 \theta}
\end{aligned}
$$

Table 5 Nomenclature of parameters in empirical formulae

\begin{tabular}{|clc|}
\hline Symbol & \multicolumn{1}{c}{ Parameter } & Unit \\
$D_{h}$ & Crater Diameter & $\mathrm{mm}$ \\
$D_{p}$ & Spherical projectile Diameter & $\mathrm{mm}$ \\
$\rho_{p}$ & Density of projectile material & $\mathrm{kg} / \mathrm{mm}^{3}$ \\
$\rho_{t}$ & Density of target material & $\mathrm{kg} / \mathrm{mm}^{3}$ \\
$V$ & Impact velocity of the projectile & $\mathrm{m} / \mathrm{s}$ \\
$c_{t}$ & Speed of sound in target material & $\mathrm{m} / \mathrm{s}$ \\
$c_{p}$ & Speed of sound in projectile material & $\mathrm{m} / \mathrm{s}$ \\
$T_{t}$ & Target plate thickness & $\mathrm{mm}$ \\
$D_{h}^{\text {min }}$ & Minor axis diameter of the crater & $\mathrm{mm}$ \\
$D_{h}^{\text {maj }}$ & Major axis diameter of the crater & $\mathrm{mm}$ \\
$\theta$ & Angle of impact & degree \\
\hline
\end{tabular}

Table 6 Empirical model constants

\begin{tabular}{|c|c|c|c|c|c|c|c|c|}
\hline $\begin{array}{c}\text { Impact Obliquity } \\
\text { Angle }\end{array}$ & $\begin{array}{c}\text { Plate Thickness } \\
(\mathbf{m m})\end{array}$ & Equation & $\boldsymbol{C}_{\mathbf{1}}$ & $\boldsymbol{p}_{\mathbf{1}}$ & $\boldsymbol{p}_{\mathbf{2}}$ & $\boldsymbol{p}_{\mathbf{3}}$ & $\mathbf{f}(\boldsymbol{\theta})$ & $\boldsymbol{C}_{\mathbf{2}}$ \\
\hline $0^{\circ}-15^{\circ}-30^{\circ}$ & $1-3-6$ & $(2)$ & 1.87 & 0.22 & 0.05 & 0 & 1 & 0 \\
\hline $35^{\circ}-45^{\circ}-60^{\circ}-75^{\circ}$ & $1-3-6$ & $(3)$ & 1.47 & 0.19 & 0.02 & 0.04 & 1 & 0.2043 \\
\hline $35^{\circ}-45^{\circ}-60^{\circ}-75^{\circ}$ & $1-3-6$ & $(4)$ & 0.60 & 0.14 & 0.06 & 1.65 & 1 & 0 \\
\hline
\end{tabular}

The constants $p_{1}, p_{2}, p_{3}, p_{4}, C_{1}, C_{2}$ in the Empirical Equations 1 to 4 are evaluated using multivariable regression technique in MATLAB software. LS-DYNA simulation results of crater diameter ratio are used as input to evaluate the constants using regression technique. The simulation results obtained for 189 cases indicate that the perforations are more or less circular and elliptical in shape for impact angles from $0^{\circ}-30^{\circ}$ and $35^{\circ}-75^{\circ}$, respectively. Therefore, the simulation results for impact angles, from $0^{\circ}-30^{\circ}$ are considered to derive a set of constants for 
normal impact and from $35^{\circ}-75^{\circ}$ are considered to derive two sets of constants for minor and major axis for oblique impact. The three sets of constants derived are tabulated in Table 6.

\section{RESULTS AND DISCUSSION}

The crater diameter values are measured in all the 189 simulation model cases computed in LS Dyna after the perforation/impact. The variation of normalised crater diameter values obtained from 1, 3 and $6 \mathrm{~mm}$ thick plates with impact velocities in the range $1000-5000 \mathrm{~m} / \mathrm{s}$ and impact angles from $0^{\circ}-30^{\circ}$ (normal impact) and $35^{\circ}-75^{\circ}$ (oblique impact) is shown in Figures 6 to 14 .

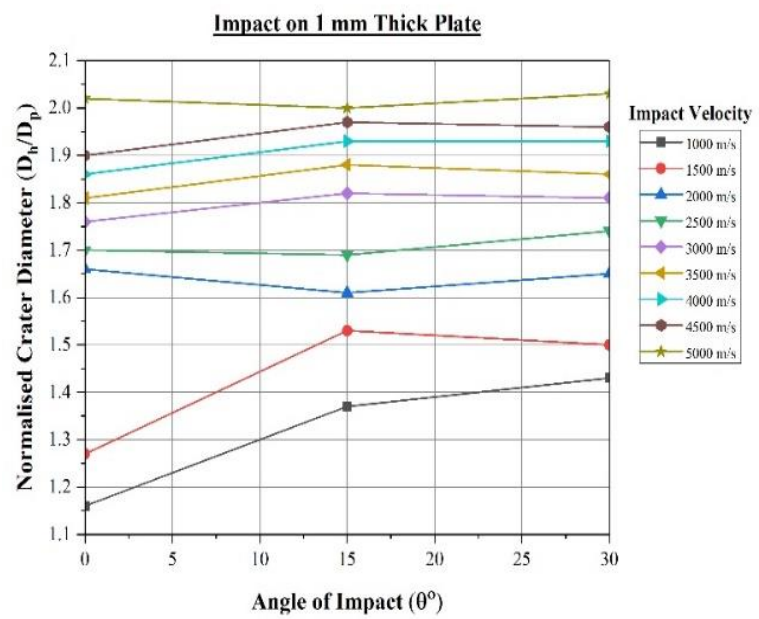

Figure 6 Variation of normalised crater dia on $1 \mathrm{~mm}$ target plate at $0^{\circ}-30^{\circ}$ impact angle

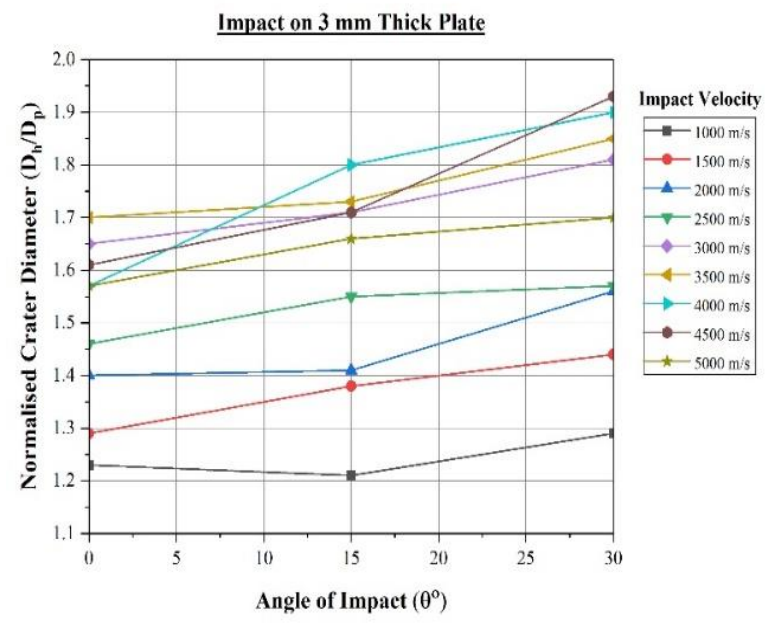

Figure 7 Variation of normalised crater dia on $3 \mathrm{~mm}$ target plate at $0^{\circ}-30^{\circ}$ impact angle

The normalised crater diameter increased with an increase in impact velocity for all the target plates for impact angle from $0^{\circ}-30^{\circ}$, as shown in Figures 6 to 8. Similarly, the normalised major crater diameter also increased with an increase in impact velocity for oblique impact angles from $35^{\circ}-75^{\circ}$ for all the target plates as shown in Figures 9 to 11 . 


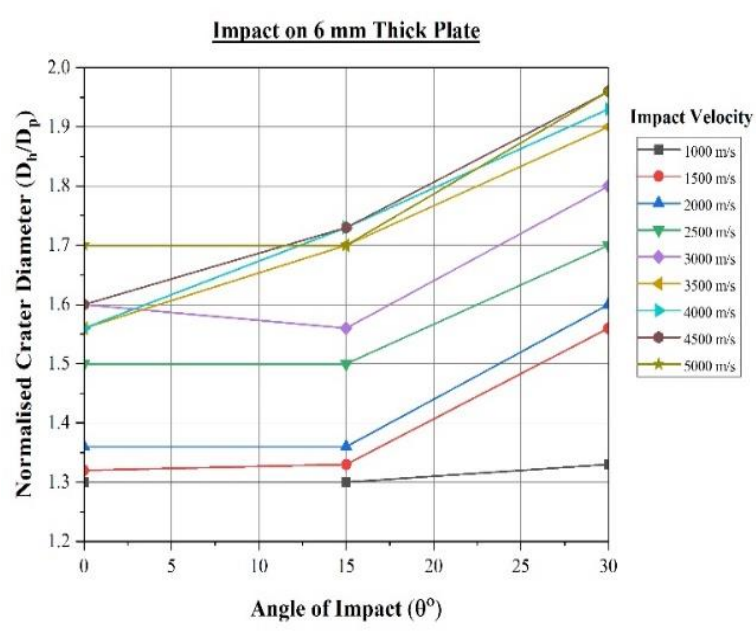

Figure 8 Variation of normalised crater dia on $6 \mathrm{~mm}$ target plate at $0^{\circ}-30^{\circ}$ impact angle
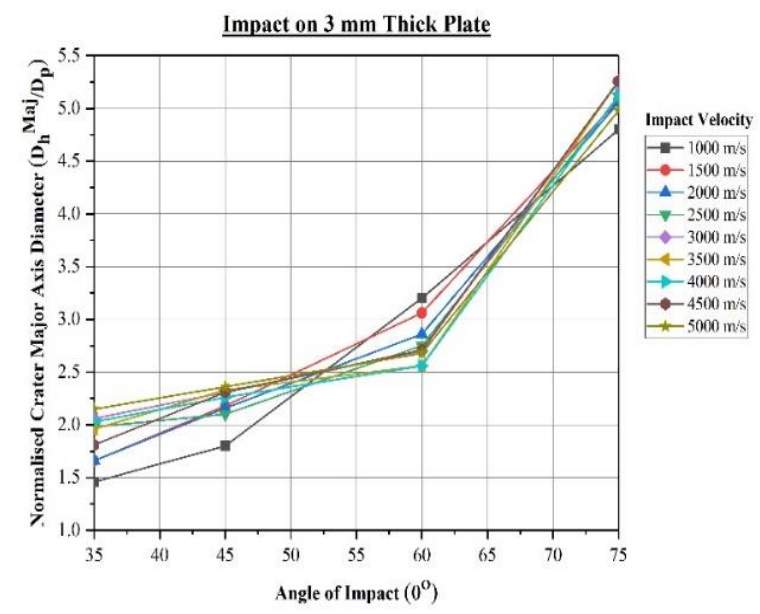

Figure 10 Variation of major axis crater dia on $3 \mathrm{~mm}$ target plate at $35^{\circ}-75^{\circ}$ impact angle

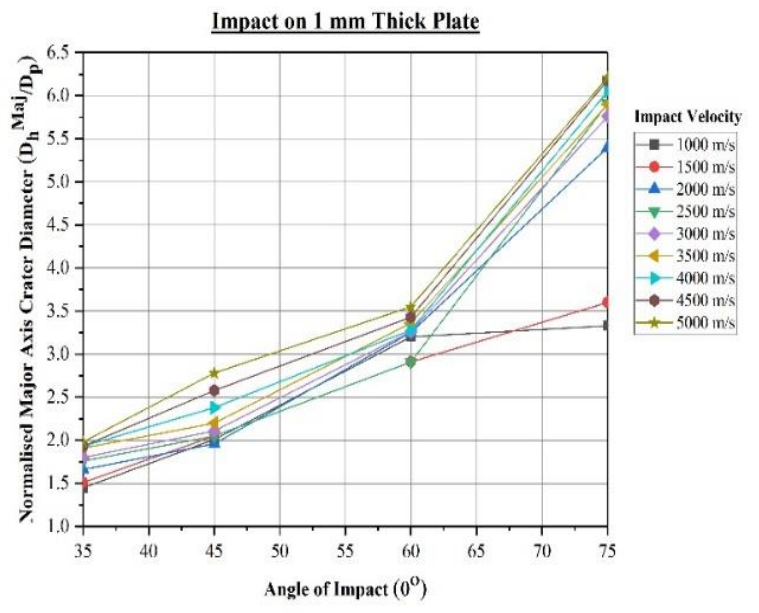

Figure 9 Variation of major axis crater dia on $1 \mathrm{~mm}$ target plate at $35^{\circ}-75^{\circ}$ impact angle

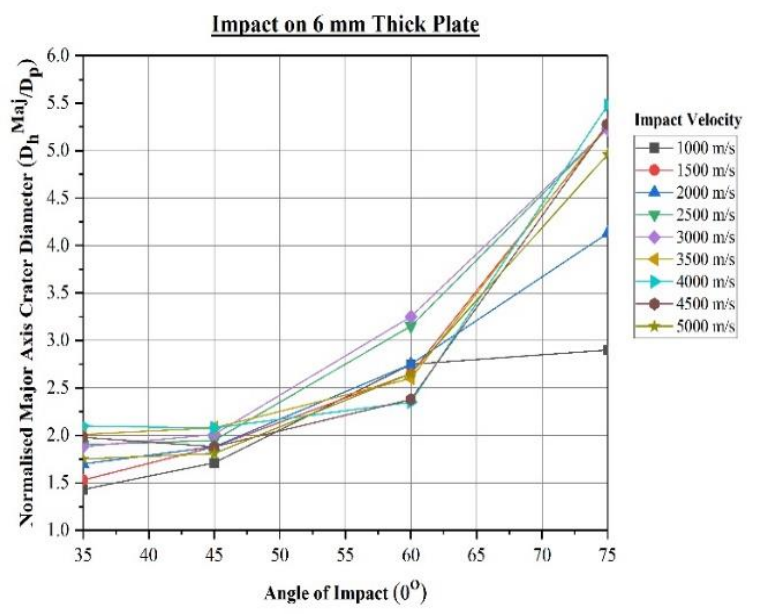

Figure 11 Variation of major axis crater dia on $6 \mathrm{~mm}$ target plate at $35^{\circ}-75^{\circ}$ impact angle

However, in case of normalised minor crater diameter for impact angles from $35^{\circ}-75^{\circ}$, no

fixed trend is observed for all the target plates shown in Figures 12 to 14. However, the crater size depends on the interaction phenomenon of the fragment with the target plate, in case of an oblique impact.

The absolute error percentage of simulation results over empirical results in normal and oblique impact conditions are shown in Figures 15 to 17 . The highest percentage error in simulation model results for crater diameter is $15 \%$ for normal impact. It is $13.76 \%$ and $28 \%$ for major and minor crater diameter for an oblique impact, respectively. 


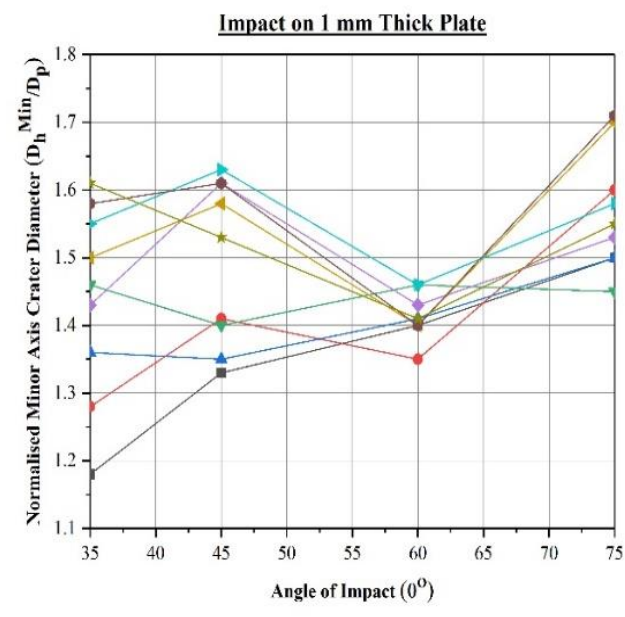

Figure 12 Variation of minor axis crater dia on $1 \mathrm{~mm}$ target plate at $35^{\circ}-75^{\circ}$ impact angle

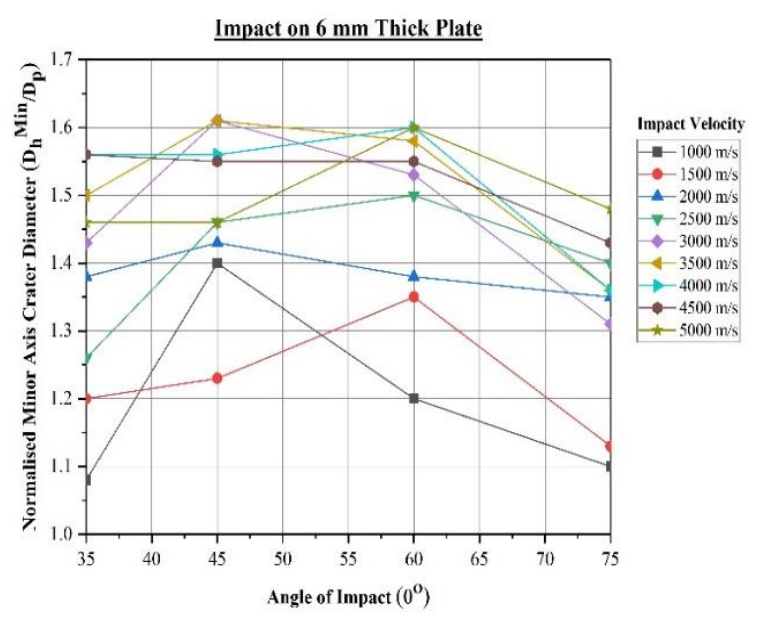

Figure 14 Variation of minor axis crater dia on $6 \mathrm{~mm}$ target plate at $35^{\circ}-75^{\circ}$ impact angle

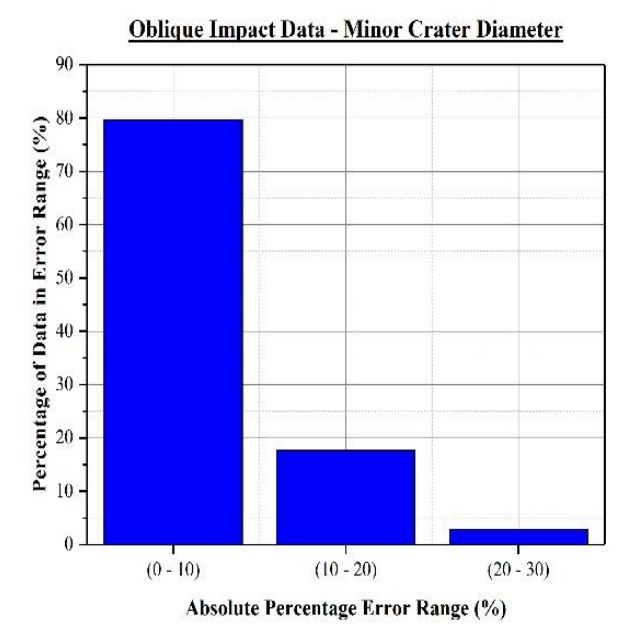

Figure 16 Percentage error in simulation results over empirical (minor crater dia)

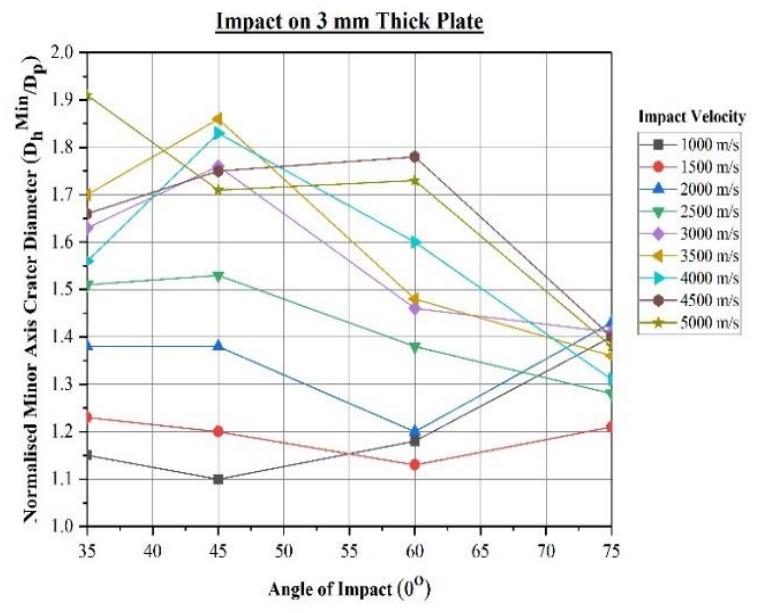

Figure 13 Variation of minor axis crater dia on $3 \mathrm{~mm}$ target plate at $35^{\circ}-75^{\circ}$ impact angle

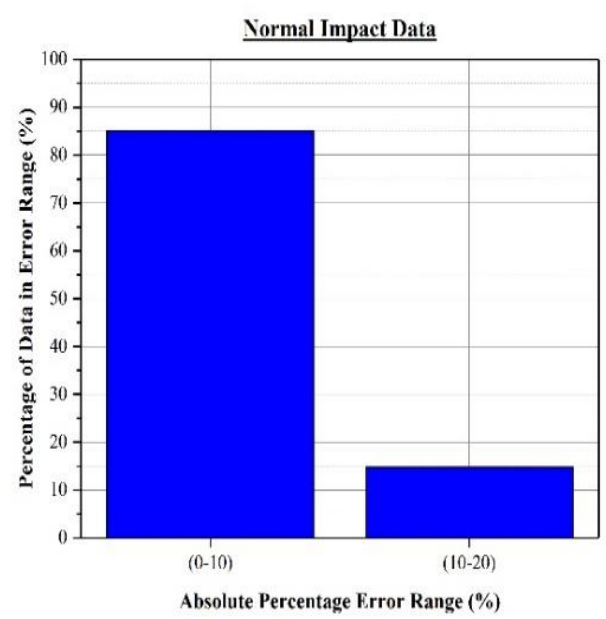

Figure 15 Percentage error in simulation results over empirical (normal crater dia)

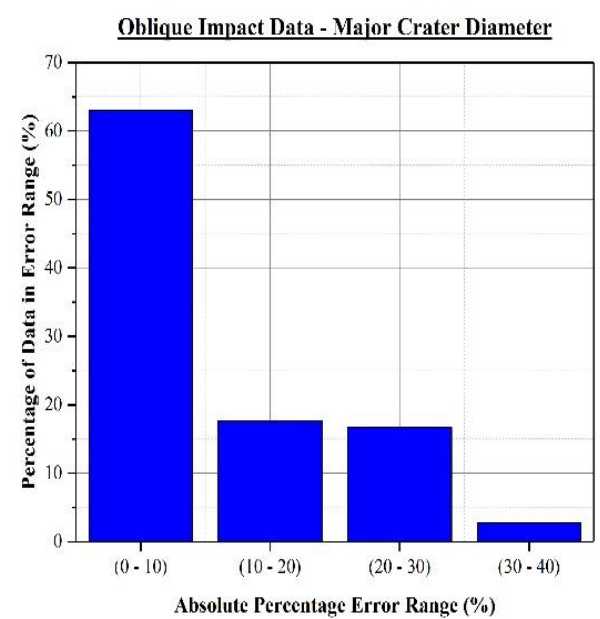

Figure 17 Percentage error in simulation results over empirical (major crater dia) 
From Figures 15 to 17, it is highlighted that, $85 \%$ of normal crater diameter data, $80 \%$ of minor crater diameter data and $63 \%$ of major crater diameter data, have less than $10 \%$ absolute error. This indicates the correctness of the simulation model code considered in this study.

Also plastic deformation in projectile is not considered at low impact velocities; however, as the impact velocity increases, the plastic deformation is localised at the projectile's front portion. Further, an increase in impact velocity leads to spall failure from the projectile's rear side, shell of spall fragment, and complete disintegration (Piekutowski, 1995 \& Piekutowski, 2003). The threshold impact velocity causing spall is a vital function of target thickness and projectile diameter ratio $\left(\mathrm{T}_{\mathrm{t}} / \mathrm{D}_{\mathrm{p}}\right)$. Also, with an increase in impact obliquity, the ricochet of fragment occurs. The debris which ricochets from the plate surface may or may not cause hole size enlargement. Thus, the increase in target plate thickness may or may not affect crater size depending on the impact obliquity.

\section{CONCLUSION}

The capability of the numerical simulation models developed using the erosion algorithm in LS Dyna to predict the material deformation behaviour at impact velocities in the range from ordnance to hyper velocities is briefly demonstrated in this study. The simulation model results have been validated with experimental and empirical model results and found to be in good agreement. The results obtained in this study would greatly assist the defence laboratories in determining the ideal fragment shape and size that are used in FGW, which can pierce a target plate and damage the structure or machinery or human behind it. Similarly, this study also assists in designing the best armour shield for protective structures or combat vehicles with optimal thickness. The current study also reiterates that numerical modelling is an efficient method of predicting material deformation behaviour.

\section{REFERENCES}


Backman, M. E. and Goldsmith, W., 1978. The mechanics of penetration of projectiles into targets," International Journal of Engineering Science, 16(1), 1-99.

Dhote, K.D., Murthy, K., Rajan, K., and Sucheendran, M., 2014. Quantification of projection angle in fragment generator warhead, Defence Technology, 10(2), 177- 183.

Dhote, K. D., Murthy, K. P., Rajan, K. M., and Sucheendran, M. M., 2015. Directional warhead design methodology for a tailored fragment beam, Central European Journal of Energetic Materials, 12(4), 637-649.

Johnson, G. R. and Cook, W.H., 1983. A constitutive model and data for metals subjected to large strains, high strain rates and high temperatures, Proceedings of the $7^{\text {th }}$ International Symposium on Ballistics, 21, 541-547.

Hosseini, M. and Abbas, H., 2006. Growth of hole in thin plates under hypervelocity impact of spherical projectiles, Thin walled structures, 44(9), 1006-1016.

Hill, S. A., 2004. Determination of an empirical model for the prediction of penetration hole diameter in thin plates from hypervelocity impact, International journal of impact engineering, 30(3), 303-321.

Gintalas, M., Ziliukas, A., and Ainsworth, R. A., 2014. New Equation for the Plastic Correction Factor for J-Integral Determination from Test Results of Three-Point-Bend Specimens, Materials Performance and Characterisation, 3(3), 125-143.

Dhote, K. D. and Verma, P., 2017. Investigation of Hole Size Formation by Steel Sphere Impacting on Thin Plate at Hypervelocity, Procedia Engineering, 173, 323-330.

Piekutowski, A. J., 1995. Fragmentation of a sphere initiated by hypervelocity impact with a thin sheet, International Journal of Impact Engineering, 17 (4-6), 627 - 638.

Piekutowski, A. J., 2003. Fragmentation initiation threshold for spheres impacting at hypervelocity, International journal of impact engineering, 29(1-10), 563 - 574. 